Article

\title{
Sequencing and Comparative Analysis of the Chloroplast Genome of Angelica polymorpha and the Development of a Novel Indel Marker for Species Identification
}

\author{
Inkyu Park ${ }^{1,+} \mathbb{\oplus}$, Sungyu Yang ${ }^{1}$, Wook Jin Kim ${ }^{1}$, Jun-Ho Song ${ }^{1}{ }^{\mathbb{D}}$, Hyun-Sook Lee ${ }^{2}$, \\ Hyun Oh Lee ${ }^{3}$, Jung-Hyun Lee ${ }^{4}$, Sang-Nag Ahn ${ }^{2}$ iD and Byeong Cheol Moon ${ }^{1, *(1)}$ \\ 1 Herbal Medicine Resources Research Center, Korea Institute of Oriental Medicine, Naju 58245, Korea; \\ pik6885@gmail.com (I.P.); sgyang81@kiom.re.kr (S.Y.); ukgene@kiom.re.kr (W.J.K.); \\ songjh@kiom.re.kr (J.-H.S.) \\ 2 Department of Agronomy, College of Agriculture and Life Sciences, Chungnam National University, \\ Daejeon 34134, Korea; leehs0107@gmail.com (H.-S.L.); ahnsn@cnu.ac.kr (S.-N.A.) \\ 3 Phyzen Genomics Institute, Seongnam 13558, Korea; dlgusdh88@phyzen.com \\ 4 Department of Biology Education, Chonnam National University, Gwangju 77, Korea; quercus@jnu.ac.kr \\ * Correspondence: bcmoon@kiom.re.kr; Tel.: +82-61-338-7100 \\ + Present address: Department of Agronomy, College of Agriculture and Life Sciences, \\ Chungnam National University, Daejeon 34134, Korea.
}

Received: 19 February 2019; Accepted: 13 March 2019; Published: 15 March 2019

\begin{abstract}
The genus Angelica (Apiaceae) comprises valuable herbal medicines. In this study, we determined the complete chloroplast (CP) genome sequence of $A$. polymorpha and compared it with that of Ligusticum officinale (GenBank accession no. NC039760). The CP genomes of A. polymorpha and L. officinale were 148,430 and 147,127 bp in length, respectively, with $37.6 \%$ GC content. Both CP genomes harbored 113 unique functional genes, including 79 protein-coding, four rRNA, and 30 tRNA genes. Comparative analysis of the two $\mathrm{CP}$ genomes revealed conserved genome structure, gene content, and gene order. However, highly variable regions, sufficient to distinguish between A. polymorpha and L. officinale, were identified in hypothetical chloroplast open reading frame1 (ycf1) and ycf2 genic regions. Nucleotide diversity $(P i)$ analysis indicated that ycf4-chloroplast envelope membrane protein $(\mathrm{cem} A)$ intergenic region was highly variable between the two species. Phylogenetic analysis revealed that $A$. polymorpha and L. officinale were well clustered at family Apiaceae. The ycf4-cemA intergenic region in A. polymorpha carried a 418 bp deletion compared with L. officinale. This region was used for the development of a novel indel marker, LYCE, which successfully discriminated between A. polymorpha and L. officinale accessions. Our results provide important taxonomic and phylogenetic information on herbal medicines and facilitate their authentication using the indel marker.
\end{abstract}

Keywords: Angelica polymorpha; Ligusticum officinale; plastid; herbal medicine; molecular marker

\section{Introduction}

In plants, the chloroplast $(\mathrm{CP})$ plays an important role in photosynthesis and carbon fixation as well as starch, fatty acid, and amino acid biosynthesis [1]. In higher plants, the $\mathrm{CP}$ genome ranges in size from 120 to $180 \mathrm{~Kb}$ and has a quadripartite structure, including a large single copy (LSC) region, a small single copy (SSC) region, and two copies of an inverted repeat (IR) region (IRa and $\mathrm{IRb}$ ) [2]. Angiosperm $\mathrm{CP}$ genomes usually contain 110-130 genes, with up to 80 protein-coding 
genes, approximately 30 transfer RNA (tRNA) genes, and four ribosomal RNA (rRNA) genes [3]. Despite the highly conserved genome structure, gene content, and gene order among plant species, $\mathrm{CP}$ genomes exhibit genomic arrangement, IR region loss, and gene loss in some angiosperms such as parasitic plants [4-9]. Advances in next generation sequencing technologies have reduced the cost and complexity of CP genome assembly compared with Sanger sequencing [10]. The CP genome has been widely used for phylogenetic analysis and molecular marker development in plant species. These molecular markers are highly useful DNA barcoding tools for the authentication and identification of plant taxa including herbal medicines. For example, matK and $r b c L$ genes in $\mathrm{CP}$ genomes are used as universal plant DNA barcodes [11]. The genus Angelica comprises valuable herbal medicines [12]. Although the CP genomes of a few Angelica species have been reported [13-17] and are available from GenBank, limited genomic information is available for the identification of Angelica species. Additional genomic information is needed to understand the utility of herbal medicines in the genus Angelica.

Insertions/deletions (indels) in $\mathrm{CP}$ genomes occur because of genomic rearrangements resulting from slipped strand mispairing, stem-loop secondary structure, and intramolecular recombination [18-20]. Indels represent intraspecific polymorphisms in plant populations [21] and are used for species identification. Indel in the $t r n L-F$ region has been widely used as a universal DNA barcode for species classification [22]. Phylogenetic relationships among 41 Poa species have been determined using indels in $t r n L-F$ and $t r n L$ introns, clustering these species into four major groups [23]. Indels in trnL-F, trnG-trnS, and trnL introns have been used for the analysis of the CP genomes of Silene latifolia and S. vulgaris. Furthermore, the authors showed that indels evolved at slightly higher rates than single nucleotide polymorphisms (SNPs) in the Silene genus [24]. In the genus Aconitum, four species have been distinguished using indels in $\mathrm{CP}$ genomes [25,26]. Furthermore, $\mathrm{CP}$ genome indels have been used to identify intraspecific variation in the genera Fagopyrum (F. tataicum vs. F. esculentum) and Ipomoea (I. nil vs. I. purpurea) $[27,28]$. Thus, indels in CP genomes are useful for phylogenetic and evolutionary analyses of plant species as well as for species identification.

The genus Angelica (family Apiaceae) is a taxonomically complex and controversial group comprising approximately 110 species with diverse morphology [29]. Ligusticum officinale is widely distributed in East Asia, and dried rhizomes of this species are used as an important herbal medicine [12]. Unfortunately, A. polymorpha is frequently misused as L. officinale in inauthentic preparations of herbal medicines in Korean herbal markets because sliced preparations of the two species are highly similar to the naked eye. To ensure a consistent pharmacological effect of herbal medicines, accurate identification of L. officinale and A. polymorpha is essential. Therefore, an objective method of analysis, such as a molecular marker, is needed for the identification of herbal medicines.

In this study, we characterized the CP genome of A. polymorpha and compared it with that of L. officinale with the aim to identify highly variable regions and understand the phylogenetic relationship between the two species. Additionally, we aimed at developing an efficient molecular marker to distinguish between the $\mathrm{CP}$ genomes of these species.

\section{Results and Discussion}

\subsection{CP Genome Organization of A. polymorpha}

The CP genome of A. polymorpha was sequenced using the Illumina MiSeq platform. Sequencing at approximately $75 \times$ coverage generated $1.25 \mathrm{~Gb}$ of paired-end reads (Table S1). The complete circular $\mathrm{CP}$ genome of A. polymorpha, completed after gap filling and manual editing, was 147,121 bp in length. Paired-end read mapping was conducted to validate the draft genome (Figure S1). The CP genome of A. polymorpha showed a quadripartite structure like in most land plants consisting of a pair of IR regions (17,870 bp each) separated by LSC ( $93,591 \mathrm{bp})$ and SSC $(17,796 \mathrm{bp})$ regions (Figure 1, Table 1$)$. The CP genome of A. polymorpha was AT-rich (62.5\%), and the AT content of LSC (64.1\%) and SSC (69\%) regions was higher than that of the IR regions (54.9\%); these data are consistent with those of other angiosperm $\mathrm{CP}$ genomes $[2,30]$. Sequences of the junctions between the LSC, SSC, and IR regions were validated 
using PCR-based sequencing (Table S2). The CP genome of A. polymorpha harbored 113 predicted genes, of which 97 were present as single copies in the LSC and SSC regions, while 17 were duplicated in the IR regions (Table S3). The 97 unique genes included 79 protein-coding genes, 30 tRNA genes, and four rRNA genes. Additionally, the CP genome of $A$. polymorpha harbored 17 intron-containing genes. Among these, 14 genes (nine protein-coding and five tRNA genes) contained a single intron, while two genes $(y c f 3$ and $c l p P$ ) contained two introns (Table S4). Of the 17 intron-containing genes, 12 genes (nine protein-coding and three tRNA genes) were located in the LSC region, one protein-coding gene in the SSC region, and four genes (two protein-coding and two tRNA genes) in the IR regions. Of the 79 protein-coding genes, six genes ( $n d h B, r p l 2, r p l 23, r p s 7, r p s 12$ and ycf15) were duplicated in the IR regions. The start codons of $n d h D$ and rps19 were ACG and GTG, respectively, which were used as an alternative to ATG. The use of ACG and GTG as start codons is a common phenomenon in various genes in CP genomes of land plants [31-33]. The protein-coding genes comprised 21,587 bp in the CP genome of $A$. polymorpha (Table S5), and codons of leucine and isoleucine were highly abundant (Figure S2A). Relative synonymous codon usage (RSCU) values revealed synonymous codon usage bias, with a high proportion of synonymous codons harboring $A$ or $T(U)$ nucleotide in the third position (Figure S2B). Overall, the genome structure, gene number, and codon usage in the CP genome of A. polymorpha were consistent with those in CP genomes of other Angelica species [13,15,17].

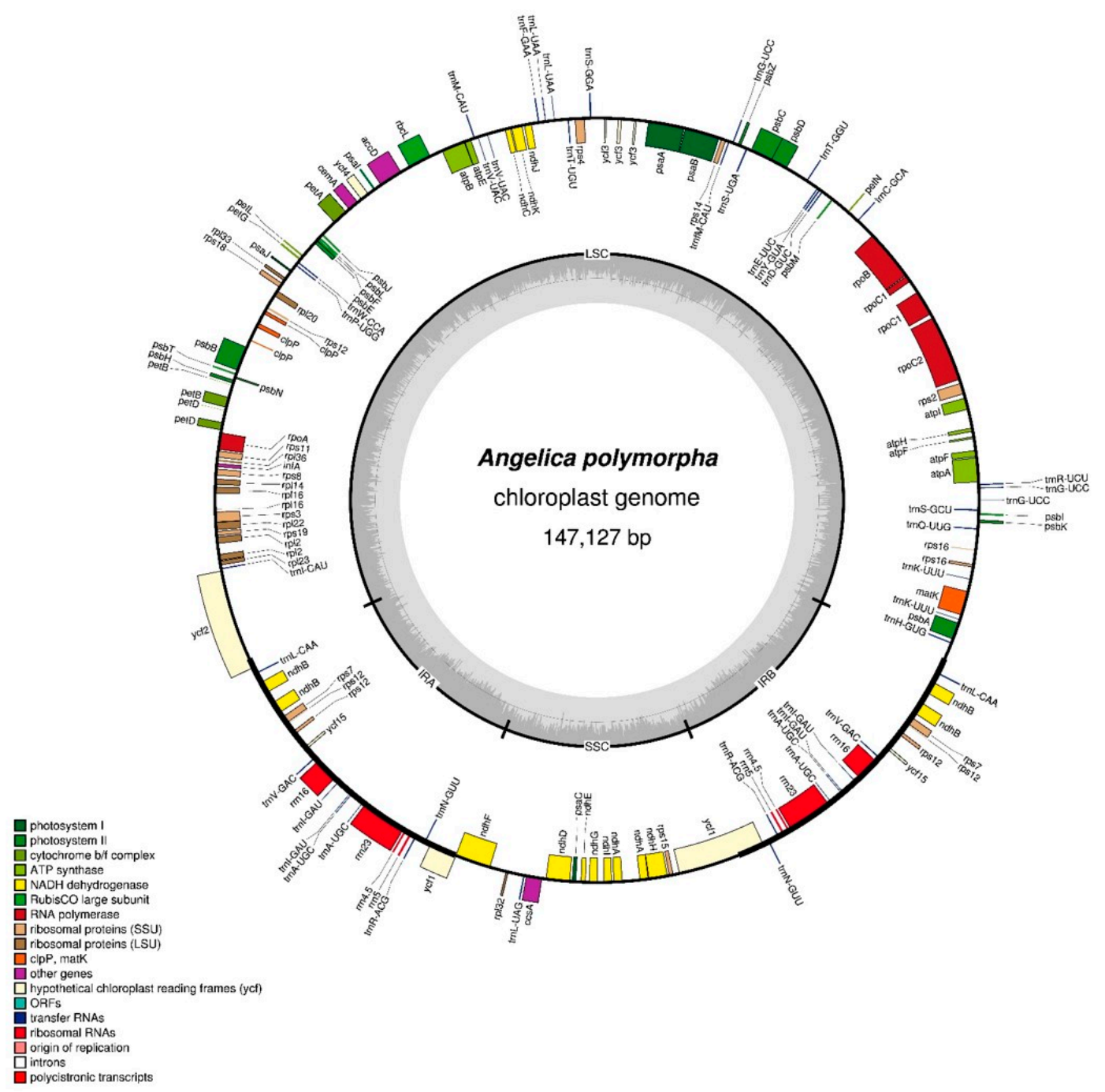

Figure 1. Circular gene map of the CP genome of A. polymorpha. Genes drawn inside the circle are transcribed clockwise, and those drawn outside the circle are transcribed counterclockwise. The darker gray inner circle represents the GC content. 
Table 1. Characteristics of the CP genomes of A. polymorpha and L. officinale.

\begin{tabular}{|c|c|c|}
\hline Characteristic $^{1}$ & A. polymorpha & L. officinale ${ }^{2}$ \\
\hline Accession number & MH260705 & NC039760 [34] \\
\hline \multicolumn{3}{|l|}{ Genome size } \\
\hline Total CP genome (bp) & 147,127 & 148,518 \\
\hline Large single copy (LSC) region (bp) & 93,591 & 93,977 \\
\hline Inverted repeat (IR) region (bp) & 17,870 & 18,467 \\
\hline Small single copy (SSC) region (bp) & 17,796 & 17,607 \\
\hline \multicolumn{3}{|l|}{ Number of unique genes } \\
\hline Total & 113 & 113 \\
\hline Protein-coding genes & 79 & 79 \\
\hline rRNA genes & 4 & 4 \\
\hline tRNA genes & 30 & 30 \\
\hline \multicolumn{3}{|l|}{ GC content $(\%)$} \\
\hline Total genome & 37.5 & 37.6 \\
\hline LSC region & 35.9 & 36.0 \\
\hline IR regions & 45.0 & 44.8 \\
\hline SSC region & 31.0 & 31.1 \\
\hline
\end{tabular}

${ }^{1} \mathrm{CP}$ : Chloroplast; LSC: Large single copy; IR: Inverted repeat; SSC: Small single copy. ${ }^{2} \mathrm{CP}$ genome of L. officinale was downloaded from GenBank.

\subsection{Analysis of Repeated Sequences in the CP Genomes of A. polymorpha and L. officinale}

Repeated sequences were abundant in the $\mathrm{CP}$ genomes of both species. These repeat sequences result in structural variation due to genomic rearrangement, gene expansion, and pseudogene formation [8,35]. Simple sequence repeats (SSRs), also known as microsatellites, comprise 1-6 nucleotides [36]. We analyzed SSRs in the CP genomes of the two species (Figure S3). The CP genomes of A. polymorpha and L. officinale harbored a similar number of SSRs (209 and 203, respectively). Most of these SSRs were located in single copy regions (LSC and SSC), as expected. The number of SSRs was similar between the SSC and IR regions. SSRs were more abundant in the intergenic spacer (IGS) region, especially the non-coding region, than in genic regions, and mononucleotide motifs were the most abundant type of repeats, followed by dinucleotide motifs, in both CP genomes (Figure S3C). We also identified tandem repeats ( $>20 \mathrm{bp}$ ) in the two CP genomes (Figure S4). Most of the tandem repeats $(20-59 \mathrm{bp})$ were located in IGS and LSC regions. The longest tandem repeat (100 bp) was present in the CP genome of L. officinale. Palindromic repeats were located in the LSC region in both $\mathrm{CP}$ genomes (Table S6). Overall, the CP genomes of A. polymorpha and L. officinale showed a similar number and type of repeats, and no polymorphism was detected between the two genomes.

\subsection{Comparative Analysis of the CP Genomes of A. polymorpha and L. officinale}

The IR regions represent the most highly conserved sequences in the CP genome [37]. The contraction and expansion of sequences at the borders of IR regions is a common evolutionary event, which is mainly responsible for variation in $\mathrm{CP}$ genome size and genomic rearrangement [38]. In this study, we analyzed the border structure of LSC, SSC, and IR regions in the two CP genomes (Figure 2). The $y c f 2$ gene was located at the LSC/IRa junction. The ycf1 pseudogene and ycf1 gene, which was located at the IRa/SSC and SSC/IRb junctions, extended into the SSC region. The location of most other genes was similar to their location in other CP genomes [28,39].

Gene content, order, and orientation were similar between the CP genomes of A. polymorpha and L. officinale. To compare $\mathrm{CP}$ genomes of the two species, we performed multiple sequence alignment of the whole $\mathrm{CP}$ genome sequences using mVISTA (Figure 3). The non-coding region was more variable than the coding region, and the IGS region was the most variable in both CP genomes. Five highly variable regions were identified in this study including three IGS regions ( $\operatorname{trnT}$ - $p s b D$, ycf4-cemA, and $y c f 2-t r n L)$ and two genic regions (ycf1 and $y c f 2$ ). To determine sequence divergence between the $\mathrm{CP}$ genomes of A. polymorpha and L. officinale, we calculated the nucleotide diversity (Pi) of the CP 
genome sequences (Figure 4). The IR regions were more highly conserved than the LSC and SSC regions, with average $\mathrm{Pi}$ values of 0.002 in IR regions and 0.009 in single copy regions (with some IR regions showing a $P i$ value of 0 ). In the LSC, ycf4-cemA exhibited a $P i$ of 0.189 , which was the highest. Although the CP genomes of both species were mostly highly conserved, the IGS regions showed divergence. High divergence in the IGS regions, including trnT-psbD, ycf4-cemA, and ycf2-trnL, because of the presence of indels, SNPs, and structural variation has been previously reported in CP genomes of other plant species [40-43]. In this study, the ycf4-cemA region was used for the development of a molecular marker to distinguish between A. polymorpha and L. officinale.

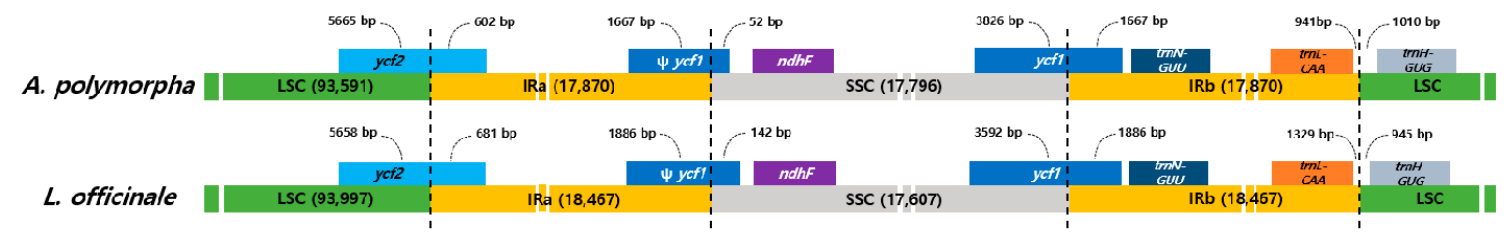

Figure 2. Comparison of $\mathrm{CP}$ genome sequences of $A$. polymorpha and L. officinale at the junctions of the LSC, IR (IRa and IRb), and SSC regions. $\psi$ : pseudogenes.
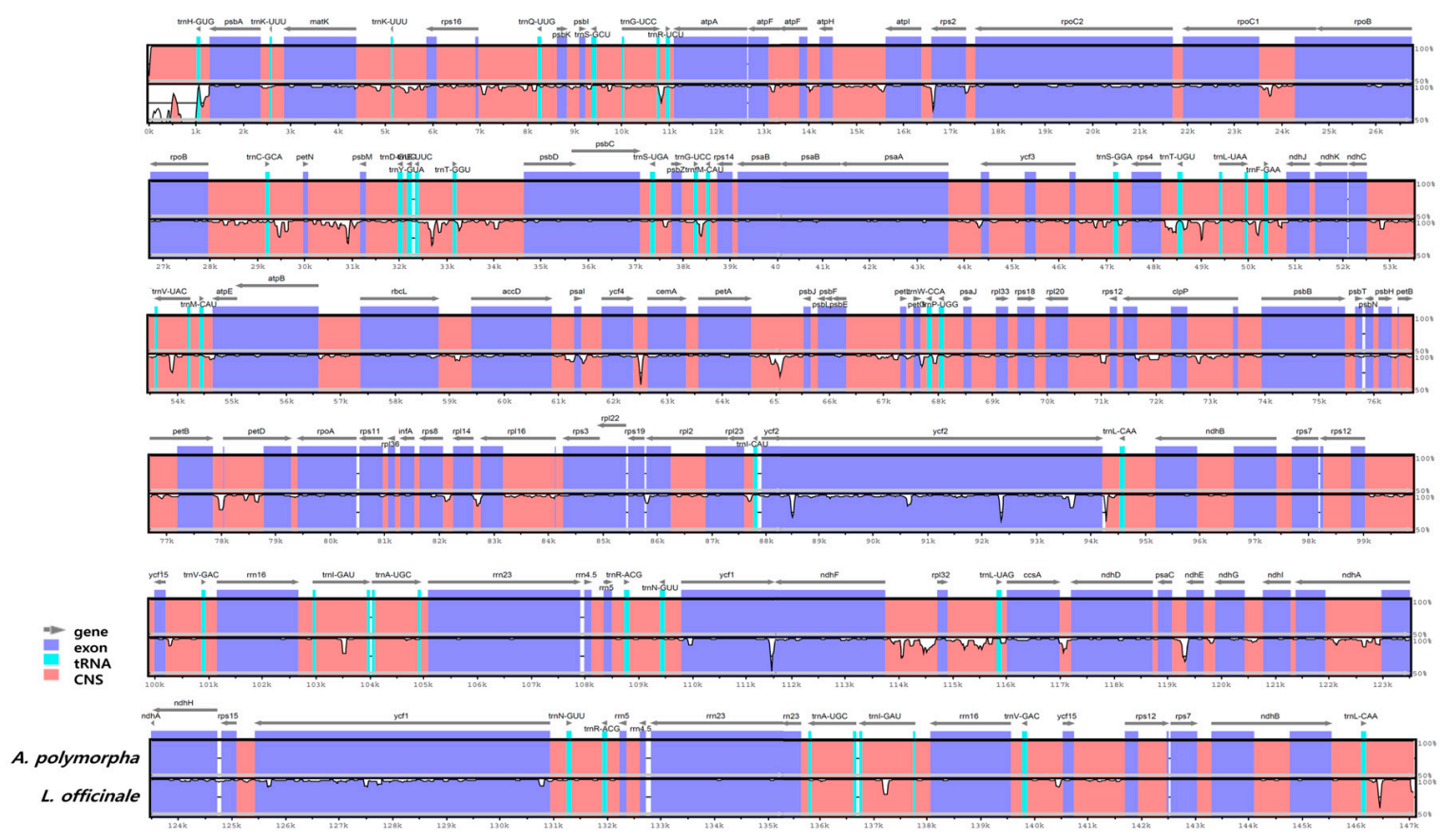

Figure 3. Comparative analysis of the CP genomes of A. polymorpha and L. officinale using mVISTA. Complete $\mathrm{CP}$ genomes of the two species were compared, with the CP genome of $A$. polymorpha used as a reference. Blue block, conserved genes; sky-blue block, tRNA and rRNA genes; red block, conserved non-coding sequences (CNSs); white block, regions polymorphic between A. polymorpha and L. officinale. 

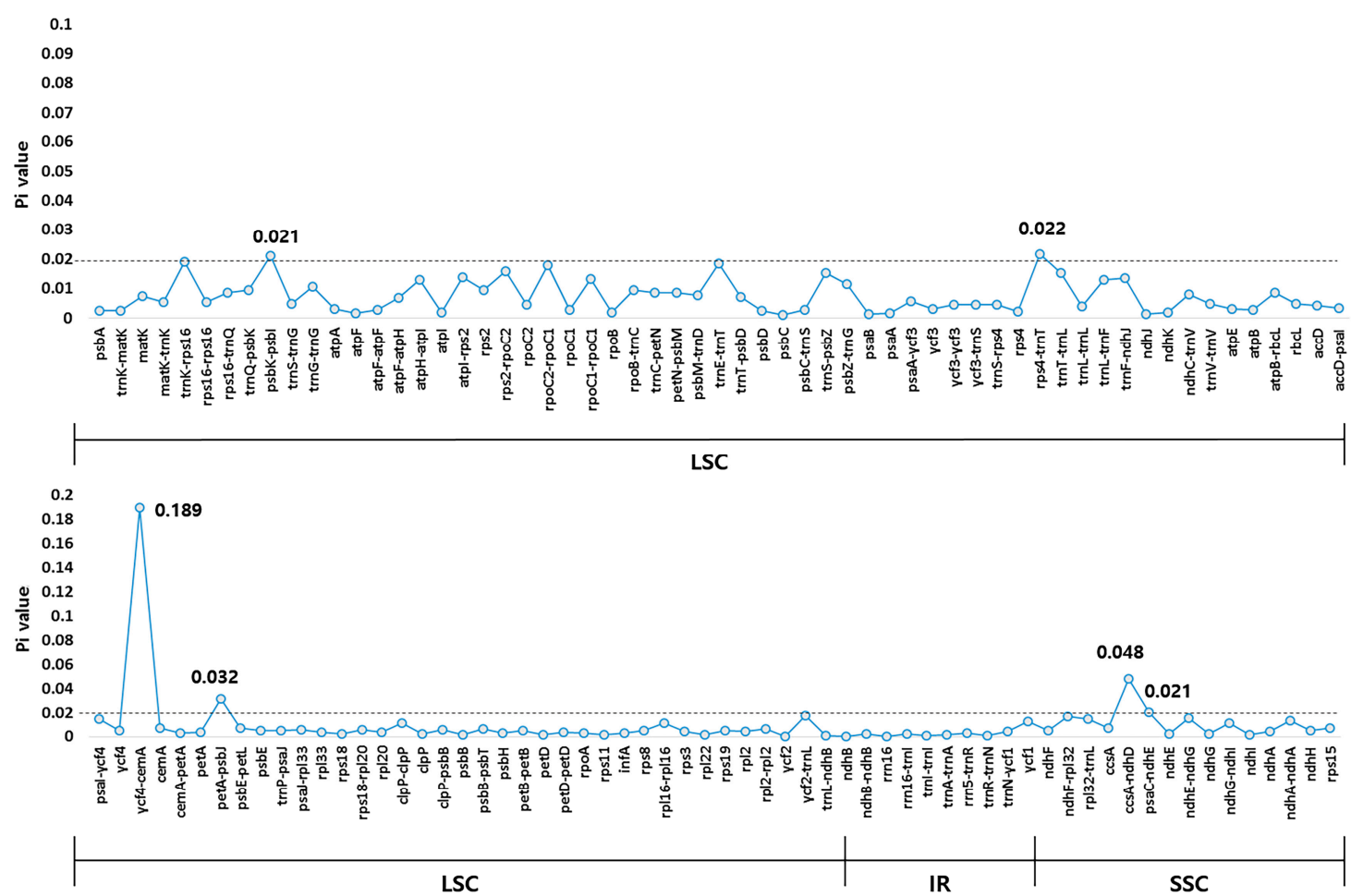

Figure 4. Comparison of nucleotide diversity $(\mathrm{Pi})$ between the $\mathrm{CP}$ genomes of $A$. polymorpha and L. officinale.

\subsection{Phylogenetic Relationship between A. polymorpha and L. officinale}

The $\mathrm{CP}$ genomes are valuable genomic resources for the reconstruction of accurate high-resolution phylogenies [44,45]. To identify the phylogenetic positions of A. polymorpha and L. officinale within the Apiaceae family, 52 protein-coding sequences shared by $33 \mathrm{CP}$ genomes were aligned over a total length of 38,279 bp (Figure 5). The maximum likelihood (ML) tree and Bayesian inference (BI) trees contained 22 of 30 nodes, with ML bootstrap values of $100 \%$ and BI posterior probabilities of 1.0. Both the ML and BI phylogenetic results indicated that Apiaceae and Araliaceae with ML bootstrap values of $100 \%$ and BI posterior probabilities of 1.0. L. tenuissimum and L. officinale clustered together. Moreover, these two Ligusticum species were closely related to Coriandrum sativum within Apiaceae. A. polymorpha was well-positioned within the genus Angelica. Foeniculum vulgare and Anethum graveolens formed a monophyletic group and a sister relationship with Petroselinum crispum within Apiaceae. The genus Angelica showed highly ML bootstrap values and BI posterior probabilities, species within this genus were well clustered according to the APG IV system [46]. However, Glehnia littoralis weakly clustered within the genus Angelica in this study. In a previous study, phylogenetic trees of Apiaceae were reconstructed using internal transcribed spacer (ITS) and CP loci [29,47,48], and our results were consistent with phylogenetic trees based on both ITS and CP loci. Genera Glehnia and Angelica showed different morphological characteristics, and their phylogenetic relationship was not clear based on whole $\mathrm{CP}$ genome sequences. However, to understand the phylogenetic relationship between Angelica and Glehnia species, in-depth investigation of other CP genomes and reinterpretation of morphological data are needed. Furthermore, taxonomic delimitation of the following four species at the genus level has changed depending on the view point of taxonomists [49-52]: Ledebouruella seseloides (=Saposhnikovia divaricata (Turcz.) Schischk), L. tenuissimum (=Conioselinum tenuissimum (Nakai) Pimenov \& Kljuykov), L. officinale (=Cnidium officinale Makino), and Peucedanum insolens [=Sillaphyton podagraria $(\mathrm{H}$. Boissieu) Pimenov]. Among these species, L. tenuissimum and L. officinale clustered within a monophyletic group in this study. We suggest that the Ligusticum taxa should be 
considered for further investigation. Taken together, our results provide insights into the phylogenetic relationship among species within Apiaceae.

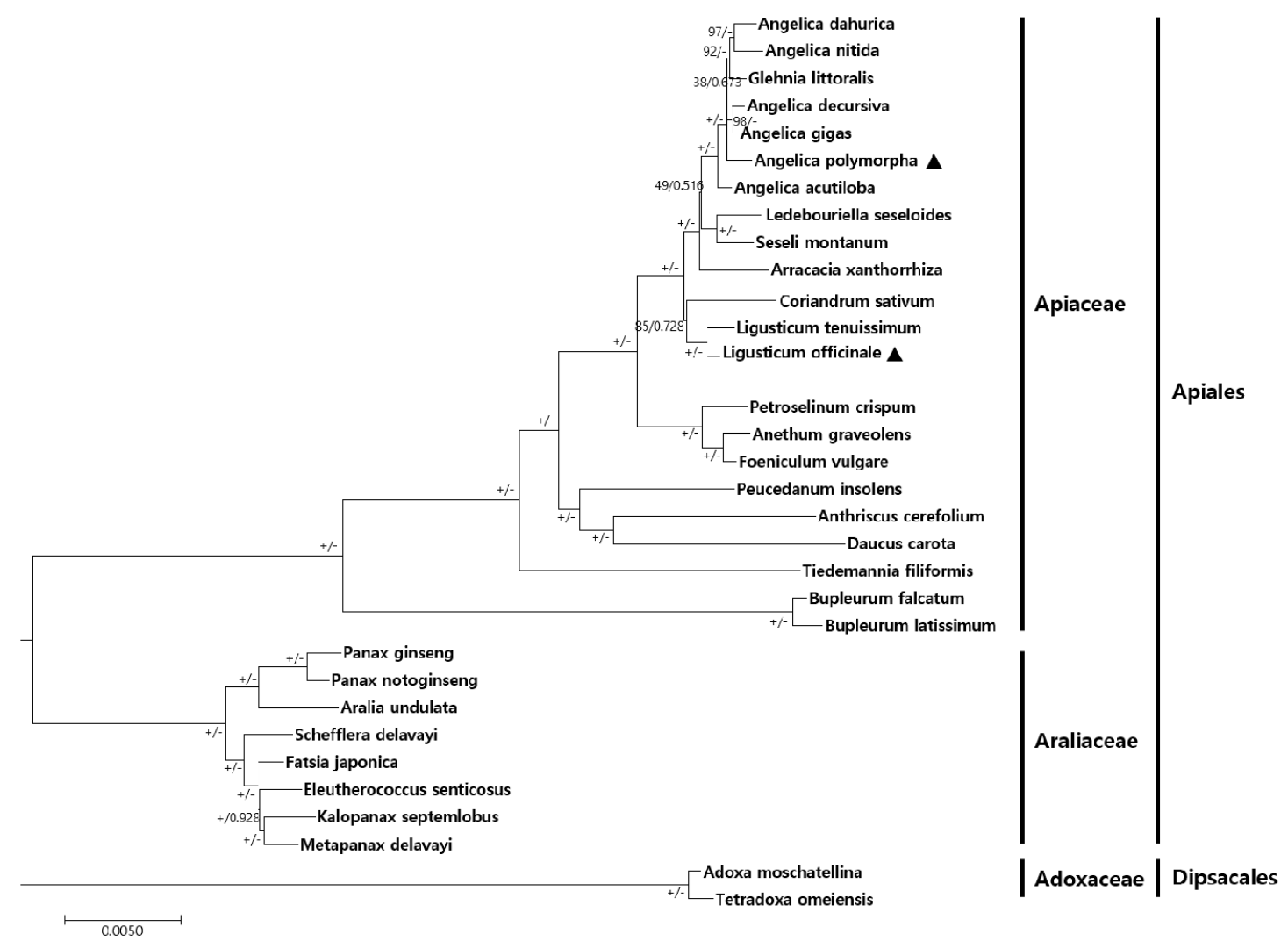

Figure 5. Phylogenetic tree showing the relationship of A. polymorpha with 31 species based on 52 protein-coding genes using maximum likelihood (ML) and Bayesian inference (BI) posterior probabilities. The ML topology is indicated with ML bootstrap support values and BI posterior probabilities at each node. The ' + ' sign indicates ML bootstrap values of $100 \%$, and the '-' sign indicates BI posterior probabilities of 1.0. Black triangles represent the $\mathrm{CP}$ genomes of $A$. polymorpha and L. officinale examined in this study.

\subsection{Development and Validation of an Indel Marker for Authentication of Cnidii Rhizoma}

In this study, we identified divergent regions in the CP genomes of A. polymorpha and L. officinale to distinguish between these two species. Results showed that the $\mathrm{CP}$ genome of $A$. polymorpha carries a 418 bp deletion in the ycf4-cemA region compared with L. officinale. To characterize these sequences, we aligned these sequences with those available in the non-redundant (NR) database of NCBI. Multiple sequence alignment revealed species-specific sequences but no copy number variation of tandem repeats. To develop indel markers, sequence-specific primers were designed in the conserved regions flanking ycf4 and cemA (Table 2). The LYCE primers successfully amplified sequences from both L. officinale and A. polymorpha (Figure 6). The indel marker was tested on 21 accessions collected from different sites in Korea using LYCE primers. These 21 samples were clearly distinguished into 12 L. officinale and nine A. polymorpha samples (Table S7). The CP DNA fragments amplified from the tested samples were sequenced to determine the exact amplicon size. The LYCE primer pair amplified a $540 \mathrm{bp}$ amplicon from L. officinale samples and a $122 \mathrm{bp}$ fragment from $A$. polymorpha samples. The predicted sizes of insertions or deletions in the CP genomes were consistent with fragment sizes amplified from L. officinale and A. polymorpha samples.

Dried rhizomes of L. officinale are used as a traditional herbal medicine in Korea [12]. Although phylogenetic analysis indicated that A. polymorpha is distant from L. officinale, a molecular approach is needed for efficient differentiation between authentic herbal medicines and adulterants that appear 
similar because of similar shaped rhizomes and sliced herbal products. Indels in CP genomes were useful for species identification and distinguishing between authentic and inauthentic herbal medicines. Previous studies have reported indel markers of CP genomes [26,53,54]. Aconitum pseudolaeve, A. longecassidatum, and A. barbatum have been clearly distinguished on the basis of variation in CP genomes using indel markers [25]. Similarly, species identification of F. tataricum and F. esculentum has been performed using the same approach [27]. Thus, indel markers play an important role in species identification and herbal medicine authentication. The LYCE indel marker developed in this study will be useful for the identification of L. officinale and authentication of Cnidii Rhizoma.

Table 2. Primers used for the development of the indel marker.

\begin{tabular}{ccc}
\hline Primer Name & Primer Sequence $\left(5^{\prime} \rightarrow \mathbf{3}^{\prime}\right)$ & Position \\
\hline LYCE-F & CGC TCA TTC TAG TCA AAG AAG ACG & ycf4-cemA \\
LYCE-R & CGC CAT CCA ATA TTT CTC TCA TGC & \\
\hline
\end{tabular}

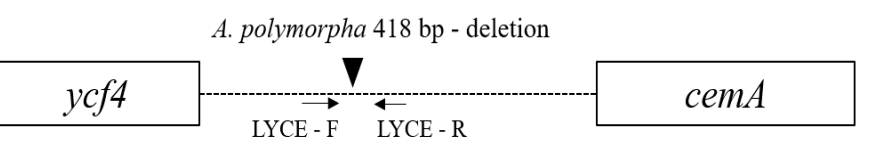

1

2

2

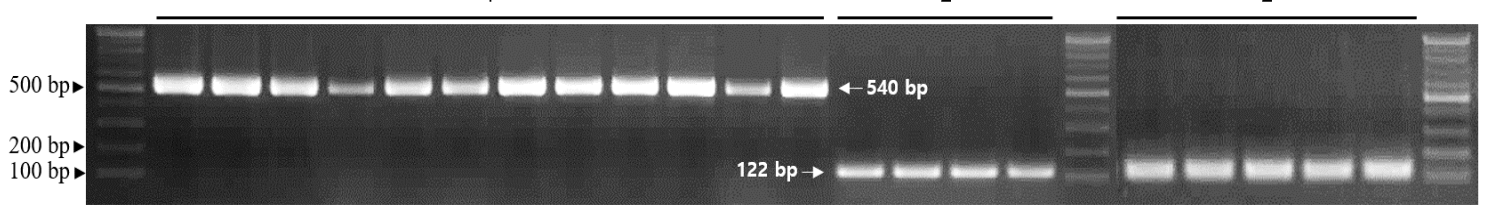

Figure 6. PCR amplification of the LYCE indel marker in 21 A. polymorpha and L. officinale accessions.

1, L. officinale; 2, A. polymorpha.

\section{Materials and Methods}

\subsection{Plant Materials}

Fresh leaves of A. polymorpha (KIOM201501014664) were collected from natural populations in Korea and used for CP genome sequencing. All samples were assigned identification numbers and registered in the Korean Herbarium of Standard Herbal Resources (Index Herbariorum code KIOM) at the Korea Institute of Oriental Medicine (KIOM, Naju, Korea). Plant samples used for CP genome analysis and indel marker validation are listed in Table S7.

\subsection{Sequencing and Assembly of the CP Genome of A. polymorpha}

DNA was extracted from leaf samples using DNeasy Plant Maxi Kit (Qiagen, Valencia, CA, USA), according to the manufacturer's instructions. Illumina short-insert paired-end sequencing libraries were constructed and sequenced using the Illumina MiSeq platform (Illumina, San Diego, CA, USA). $\mathrm{CP}$ genome sequences were determined from the de novo assembly of low-coverage whole genome sequences. Trimmed paired-end reads (Phred score $\geq 20$ ) were assembled using the CLC genome assembler ver. 4.06 beta (CLC Inc., Rarhus, Denmark) with default parameters. Principal contigs representing the $\mathrm{CP}$ genome were retrieved from the total collection of contigs using Nucmer [55] and aligned with the reference CP genome sequence of Angelica acutiloba (KT963036). De novo SOAP gap closer was performed to fill gaps based on the aligned paired-end reads [56]. 


\subsection{Annotation and Comparative Analysis}

Gene annotation of the CP genome of A. polymorpha was performed using GeSeq [57], and annotation results were concatenated using an in-house script pipeline. Protein-coding sequences were manually curated and confirmed using Artemis [58] and checked against the NCBI protein database. Sequences of tRNAs were confirmed using tRNAscan-SE 1.21 [59], and those of the IR regions were confirmed using IR finder and RepEx [60,61]. Circular maps of the A. polymorpha CP genome were generated using OGDRAW [62]. The GC content and RSCU values were analyzed using MEGA6 software [63]. Sequences of LSC/IR, IR/SSC, SSC/IR, and IR/LSC junctions were validated using PCR-based sequencing. Primer information and sequence alignment results are listed in Tables S8 and S2, respectively. CP genome sequence reads were mapped onto the complete genome using Burrows-Wheel Aligner ver. 0.7.25 [64]. The complete CP genome sequence of $A$. polymorpha was deposited in NCBI under the accession number MH260705. Comparative analysis of the CP genomes of A. polymorpha and L. officinale was performed using the mVISTA program in Shuffle-LAGAN mode, with the $A$. polymorpha $\mathrm{CP}$ genome as a reference [65]. DnaSP version 5.1 was used to calculate nucleotide diversity $(\mathrm{Pi}$ ) between A. polymorpha and L. officinale CP genomes [66].

\subsection{Analysis of SSRs and Tandem and Palindromic Repeats in CP Genomes of A. polymorpha and L. officinale}

Tandem repeats were at least $20 \mathrm{bp}$ in length, with minimum alignment score and maximum period size set at 50 and 500, respectively. The identity of repeats was set at $\geq 90 \%$. SSRs were detected using MISA, with minimum repeat number set at 10, 5, 4, 3, 3, and 3 for mono-, di-, tri-, tetra-, pentaand hexanucleotides, respectively [67]. The IR regions were detected using the Inverted Repeats Finder with default parameters. The IR regions were required to be at least $20 \mathrm{bp}$ in length with $90 \%$ sequence similarity [68].

\subsection{Phylogenetic Analysis}

A total of 33 CP genomes, including 23 Apiaceae, eight Araliaceae, and two outgroup species (Adoxa moschatellina (GenBank accession no. NC_034792) and Tetradoxa omeiensis (GenBank accession no. NC_034794)), were used for phylogenetic analysis. Of these, 32 CP genomes were downloaded from the NCBI GenBank database (Table S9). Alignments of 52 conserved protein-coding genes were used to construct molecular phylogenetic trees with MAFFT [69] and then manually adjusted using Bioedit [70]. The best-fitting nucleotide substitution model was determined using the Akaike Information Criterion (AIC) in JModeltest V2.1.10 [71]. The GTR+I+G model was used in both species. ML analysis was performed using MEGA6 with 1000 bootstrap replicates [59], and BI analysis was performed in MrBayes 3.2.2 using the Markov Chain Monte Carlo (MCMC) method, with two independent runs (four chains each) for one million generations. Phylogenetic trees were sampled every 1000 generations, with the first 25\% discarded as burn-in. Phylogenetic trees were determined from 50\% majority-rule consensus trees to estimate PP values [72].

\subsection{Development and Validation of the LYCE Indel}

Regions containing indels were selected based on sequence similarities detected with mVISTA. To amplify these regions, primers were designed using Primer-BLAST (NCBI). Indel regions were amplified from $20 \mathrm{ng}$ of genomic DNA in a $20 \mu \mathrm{L}$ reaction volume containing Solg ${ }^{\mathrm{TM}} 2 \mathrm{X}$ Taq PCR Smart Mix 1 (Solgent, Daejeon, Korea) and 10 pmol of each primer (Bioneer, Daejeon, Korea). Amplification was performed on a Pro Flex PCR system (Applied Biosystems, Waltham, MA, USA) under the following conditions: initial denaturation at $95^{\circ} \mathrm{C}$ for $2 \mathrm{~min}$, followed by 35 cycles of denaturation at $95^{\circ} \mathrm{C}$ for $40 \mathrm{~s}$, annealing at $60^{\circ} \mathrm{C}$ for $40 \mathrm{~s}$, and extension at $72{ }^{\circ} \mathrm{C}$ for $50 \mathrm{~s}$, and lastly a final extension at $72{ }^{\circ} \mathrm{C}$ for $5 \mathrm{~min}$. PCR products were separated on $2 \%$ agarose gels at $150 \mathrm{~V}$ for $40 \mathrm{~min}$. The specificity of the indel marker and variability in indel regions between A. polymorpha and L. officinale were verified based on PCR amplification profiles of all 21 samples. All samples were assigned identification 
numbers, and voucher specimens were deposited in the Korean Herbarium of Standard Herbal Resources (IH code KIOM). In addition, to confirm that PCR product sizes were accurate, each PCR product was isolated using a gel extraction kit (Qiagen, Valencia, CA, USA), subcloned into the pGEM-T Easy vector (Promega, Madison, WI, USA), and sequenced on a DNA sequence analyzer (ABI 3730, Applied Biosystems Inc., Foster City, CA, USA).

\section{Conclusions}

In this study, we sequenced the CP genome of $A$. polymorpha and compared it with that of L. officinale. The CP genomes of both species were highly conserved with respect to gene content, gene orientation, and GC content; however, local sequence variations were detected between A. polymorpha and L. officinale. The most divergent regions between the two $\mathrm{CP}$ genomes were found in three non-coding IGS regions ( $t r n T-p s b D, y c f 4$-cemA, and ycf2-trnL) and two genic regions (ycf1 and $y c f 2$ ). Analysis of nucleotide diversity revealed the highest diversity in the ycf4-cemA region. The results of phylogenetic analysis of CP genomes were consistent with those of previous studies. Additionally, we developed a novel indel marker, LYCE, based on sequence variation in the ycf4-cemA region to discriminate the herbal medicine L. officinale from the adulterant A. polymorpha. Thus, analysis of CP genomes is key for species identification, taxonomic classification, and evolutionary analysis of the Apiaceae family members. The LYCE indel marker will be useful for the authentication of Cnidii Rhizoma.

Supplementary Materials: The following are available online, Figure S1: Distribution of paired-end reads mapped onto the complete chloroplast (CP) genome sequence of $A$. polymorpha, Figure S2: Codon frequencies and relative synonymous codon usage (RSCU) values of the CP genomes of A. polymorpha and L. officinale. (A) Amino acid frequencies in protein-coding genes. (B) Codon usage for 20 amino acids and stop codons in 78 protein-coding genes, Figure S3: Distribution of simple sequence repeats (SSRs) in the CP genomes of A. polymorpha and L. officinale. (A) Number of SSRs in CP genomes. (B) Number of SSRs in exons, introns and intergenic spacer (IGS) regions. (C) Number of different types of SSRs in CP genomes, Figure S4: Analysis of tandem repeats in the CP genomes of A. polymorpha and L. officinale. (A) Distribution of tandem repeats in different regions of CP genomes. (B) Number of tandem repeats in IGS regions, exons, and introns. (C) Distribution of tandem repeats of variable lengths in CP genomes, Table S1: Details of the raw sequence reads and CP genome assembly of $A$. polymorpha, Table S2: PCR-based sequence validation of junctions between the large single copy (LSC), small single copy (SSC), and inverted repeat (IRa and IRb) regions in the CP genome of A. polymorpha, Table S3: List of genes and encoded proteins identified in the CP genomes of A. polymorpha and L. officinale. Table S4: List of intron-containing genes in the CP genomes of $A$. polymorpha and L. officinale, Table S5: Codon-anticodon recognition patterns and codon usage in the CP genomes of A. polymorpha and L. officinale, Table S6: Details of palindromic repeats present in the LSC region of the CP genomes of A. polymorpha and L. officinale, Table S7: List of A. polymorpha and L. officinale accessions used in this study, Table S8: List of primers used for the validation of the CP genome sequence of A. polymorpha, Table S9: List of CP genomes downloaded from NCBI for phylogenetic analysis.

Author Contributions: Experimental design, I.P.; collection and identification of plant material, S.Y., J.-H.L.; experiment execution, W.J.K.; Genome analysis, I.P., J.-H.S., H.-S.L., and H.O.L.; manuscript draft preparation, I.P.; manuscript review, I.P., S.-N.A., and B.C.M. All authors contributed to the experiments and approved the final manuscript.

Funding: This work was supported by a grant on the Development of Foundational Techniques for the Domestic Production of Authentic Herbal Medicines based on the Establishment of Molecular Authentication Systems (K18403) from the Korea Institute of Oriental Medicine (KIOM), Republic of Korea.

Acknowledgments: The authors thank the "Classification and Identification Committee of the KIOM" for the identification of plant materials, and the Herbarium of Korea Standard Herbal Resources (Index Herbariorum code KIOM) for the provision of plant materials.

Conflicts of Interest: The authors declare no conflict of interest.

\section{References}

1. Qian, J.; Song, J.; Gao, H.; Zhu, Y.; Xu, J.; Pang, X.; Yao, H.; Sun, C.; Li, X.; Li, C.; et al. The complete chloroplast genome sequence of the medicinal plant Salvia miltiorrhiza. PLoS ONE 2013, 8, e57607. [CrossRef] [PubMed] 
2. Yang, M.; Zhang, X.; Liu, G.; Yin, Y.; Chen, K.; Yun, Q.; Zhao, D.; Al-Mssallem, I.S.; Yu, J. The complete chloroplast genome sequence of date palm (Phoenix dactylifera L.). PLoS ONE 2010, 5, e12762. [CrossRef] [PubMed]

3. Jansen, R.K.; Ruhlman, T.A. Plastid genomes of seed plants. In Genomics of Chloroplasts and Mitochondria; Springer: Dordrecht, The Netherlands, 2012; pp. 103-126.

4. Weng, M.-L.; Blazier, J.C.; Govindu, M.; Jansen, R.K. Reconstruction of the ancestral plastid genome in Geraniaceae reveals a correlation between genome rearrangements, repeats, and nucleotide substitution rates. Mol. Biol. Evol. 2013, 31, 645-659. [CrossRef] [PubMed]

5. Cosner, M.E.; Jansen, R.K.; Palmer, J.D.; Downie, S.R. The highly rearranged chloroplast genome of Trachelium caeruleum (Campanulaceae): Multiple inversions, inverted repeat expansion and contraction, transposition, insertions/deletions, and several repeat families. Curr. Genet. 1997, 31, 419-429. [CrossRef] [PubMed]

6. Chumley, T.W.; Palmer, J.D.; Mower, J.P.; Fourcade, H.M.; Calie, P.J.; Boore, J.L.; Jansen, R.K. The complete chloroplast genome sequence of Pelargonium $\mathrm{x}$ hortorum: Organization and evolution of the largest and most highly rearranged chloroplast genome of land plants. Mol. Biol. Evol. 2006, 23, 2175-2190. [CrossRef] [PubMed]

7. Lin, C.S.; Chen, J.J.; Huang, Y.T.; Chan, M.T.; Daniell, H.; Chang, W.J.; Hsu, C.T.; Liao, D.C.; Wu, F.H.; Lin, S.Y.; et al. The location and translocation of $n d h$ genes of chloroplast origin in the Orchidaceae family. Sci. Rep. 2015, 5, 9040. [CrossRef] [PubMed]

8. Frailey, D.C.; Chaluvadi, S.R.; Vaughn, J.N.; Coatney, C.G.; Bennetzen, J.L. Gene loss and genome rearrangement in the plastids of five Hemiparasites in the family Orobanchaceae. BMC Plant Biol. 2018, 18, 30. [CrossRef] [PubMed]

9. Li, Y.; Zhou, J.G.; Chen, X.L.; Cui, Y.X.; Xu, Z.C.; Li, Y.H.; Song, J.Y.; Duan, B.Z.; Yao, H. Gene losses and partial deletion of small single-copy regions of the chloroplast genomes of two hemiparasitic Taxillus species. Sci. Rep. 2017, 7, 12834. [CrossRef] [PubMed]

10. Varshney, R.K.; Nayak, S.N.; May, G.D.; Jackson, S.A. Next-generation sequencing technologies and their implications for crop genetics and breeding. Trends Biotechnol. 2009, 27, 522-530. [CrossRef] [PubMed]

11. Dong, W.; Liu, J.; Yu, J.; Wang, L.; Zhou, S. Highly variable chloroplast markers for evaluating plant phylogeny at low taxonomic levels and for DNA barcoding. PLoS ONE 2012, 7, e35071. [CrossRef] [PubMed]

12. Korea Institute of Oriental Medicine (KIOM). Defining Dictionary for Medicinal Herbs. 2019. Available online: http:/ / boncho.kiom.re.kr/codex/ (accessed on 2 January 2019).

13. Tian, E.; Liu, Q.; Chen, W.; Li, F.; Chen, A.; Li, C.; Chao, Z. Characterization of complete chloroplast genome of Angelica sinensis (Apiaceae), an endemic medical plant to China. Mitochondrial DNA B Resour. 2019, 4, 158-159. [CrossRef]

14. Zhang, H.; Wang, X.-F.; Cao, D.; Niu, J.-F.; Wang, Z.-Z. The complete chloroplast genome sequence of Angelica tsinlingensis (Apioideae). Mitochondrial DNA B Resour. 2018, 3, 480-481. [CrossRef]

15. Deng, Y.-Q.; Wen, J.; Yu, Y.; He, X.-J. The complete chloroplast genome of Angelica nitida. Mitochondrial DNA B Resour. 2017, 2, 694-695. [CrossRef]

16. Choi, S.A.; Kim, Y.J.; Lee, W.K.; Kim, K.Y.; Kim, J.H.; Seong, R.S. The complete chloroplast genome of the medicinal plant Angelica decursiva (Apiaceae) in Peucedani Radix. Mitochondrial DNA B Resour. 2016, 1, 210-211. [CrossRef]

17. Choi, S.A.; Kim, Y.; Kim, K.-Y.; Kim, J.H.; Seong, R.S. The complete chloroplast genome sequence of the medicinal plant, Angelica gigas (Apiaceae). Mitochondrial DNA B Resour. 2016, 1, 280-281. [CrossRef]

18. Levinson, G.; Gutman, G.A. Slipped-strand mispairing: A major mechanism for DNA sequence evolution. Mol. Biol. Evol. 1987, 4, 203-221. [PubMed]

19. Kelchner, S.A. The evolution of non-coding chloroplast DNA and its application in plant systematics. Ann. Mo. Bot. Gard. 2000, 87, 482-498. [CrossRef]

20. Ogihara, Y.; Terachi, T.; Sasakuma, T. Intramolecular recombination of chloroplast genome mediated by short direct-repeat sequences in wheat species. Proc. Natl. Acad. Sci. USA 1988, 85, 8573-8577. [CrossRef] [PubMed]

21. Hamilton, M.B.; Braverman, J.M.; Soria-Hernanz, D.F. Patterns and relative rates of nucleotide and insertion/deletion evolution at six chloroplast intergenic regions in new world species of the Lecythidaceae. Mol. Biol. Evol. 2003, 20, 1710-1721. [CrossRef] [PubMed] 
22. Chen, C.W.; Huang, Y.M.; Kuo, L.Y.; Nguyen, Q.D.; Luu, H.T.; Callado, J.R.; Farrar, D.R.; Chiou, W.L. trnL-F is a powerful marker for DNA identification of field vittarioid gametophytes (Pteridaceae). Ann. Bot. 2013, 111, 663-673. [CrossRef] [PubMed]

23. Stoneberg Holt, S.D.; Horova, L.; Bures, P. Indel patterns of the plastid DNA trnL- trnF region within the genus Poa (Poaceae). J. Plant Res. 2004, 117, 393-407. [CrossRef] [PubMed]

24. Ingvarsson, P.K.; Ribstein, S.; Taylor, D.R. Molecular evolution of insertions and deletion in the chloroplast genome of silene. Mol. Biol. Evol. 2003, 20, 1737-1740. [CrossRef] [PubMed]

25. Park, I.; Yang, S.; Choi, G.; Kim, W.J.; Moon, B.C. The complete chloroplast genome sequences of Aconitum pseudolaeve and Aconitum longecassidatum, and development of molecular markers for distinguishing species in the Aconitum Subgenus Lycoctonum. Molecules 2017, 22, 2012. [CrossRef] [PubMed]

26. Park, I.; Kim, W.J.; Yang, S.; Yeo, S.M.; Li, H.; Moon, B.C. The complete chloroplast genome sequence of Aconitum coreanum and Aconitum carmichaelii and comparative analysis with other Aconitum species. PLoS ONE 2017, 12, e0184257. [CrossRef] [PubMed]

27. Cho, K.S.; Yun, B.K.; Yoon, Y.H.; Hong, S.Y.; Mekapogu, M.; Kim, K.H.; Yang, T.J. Complete chloroplast genome sequence of tartary buckwheat (Fagopyrum tataricum) and comparative analysis with common buckwheat (F. esculentum). PLoS ONE 2015, 10, e0125332. [CrossRef] [PubMed]

28. Park, I.; Yang, S.; Kim, W.J.; Noh, P.; Lee, H.O.; Moon, B.C. The complete chloroplast genomes of six Ipomoea species and indel marker development for the discrimination of authentic Pharbitidis Semen (Seeds of I. nil or I. purpurea). Front. Plant Sci. 2018, 9, 965. [CrossRef] [PubMed]

29. Liao, C.; Downie, S.R.; Li, Q.; Yu, Y.; He, X.; Zhou, B. New insights into the phylogeny of Angelica and its allies (Apiaceae) with emphasis on East Asian species, inferred from nrDNA, cpDNA, and morphological evidence. Syst. Bot. 2013, 38, 266-281. [CrossRef]

30. Raubeson, L.A.; Peery, R.; Chumley, T.W.; Dziubek, C.; Fourcade, H.M.; Boore, J.L.; Jansen, R.K. Comparative chloroplast genomics: Analyses including new sequences from the angiosperms Nuphar advena and Ranunculus macranthus. BMC Genom. 2007, 8, 174. [CrossRef] [PubMed]

31. Sasaki, T.; Yukawa, Y.; Miyamoto, T.; Obokata, J.; Sugiura, M. Identification of RNA editing sites in chloroplast transcripts from the maternal and paternal progenitors of tobacco (Nicotiana tabacum): Comparative analysis shows the involvement of distinct trans-factors for $n d h B$ editing. Mol. Biol. Evol. 2003, 20, 1028-1035. [CrossRef] [PubMed]

32. Gao, L.; Yi, X.; Yang, Y.X.; Su, Y.J.; Wang, T. Complete chloroplast genome sequence of a tree fern Alsophila spinulosa: Insights into evolutionary changes in fern chloroplast genomes. BMC Evol. Biol. 2009, 9, 130. [CrossRef] [PubMed]

33. Sanchez-Puerta, M.V.; Abbona, C.C. The chloroplast genome of Hyoscyamus niger and a phylogenetic study of the tribe Hyoscyameae (Solanaceae). PLoS ONE 2014, 9, e98353. [CrossRef] [PubMed]

34. Park, I.; Yang, S.; Kim, W.J.; Noh, P.; Lee, H.O.; Moon, B.C. The complete chloroplast genome of Cnidium officinale Makino. Mitochondrial DNA B Resour. 2018, 3, 490-491. [CrossRef]

35. Perry, A.S.; Wolfe, K.H. Nucleotide substitution rates in legume chloroplast DNA depend on the presence of the inverted repeat. J. Mol. Evol. 2002, 55, 501-508. [CrossRef] [PubMed]

36. Zalapa, J.E.; Cuevas, H.; Zhu, H.; Steffan, S.; Senalik, D.; Zeldin, E.; McCown, B.; Harbut, R.; Simon, P. Using next-generation sequencing approaches to isolate simple sequence repeat (SSR) loci in the plant sciences. Am. J. Bot. 2012, 99, 193-208. [CrossRef] [PubMed]

37. Daniell, H.; Lin, C.S.; Yu, M.; Chang, W.J. Chloroplast genomes: Diversity, evolution, and applications in genetic engineering. Genome biology 2016, 17, 134. [CrossRef] [PubMed]

38. Khakhlova, O.; Bock, R. Elimination of deleterious mutations in plastid genomes by gene conversion. Plant J. 2006, 46, 85-94. [CrossRef] [PubMed]

39. Park, I.; Kim, W.J.; Yeo, S.M.; Choi, G.; Kang, Y.M.; Piao, R.; Moon, B.C. The complete chloroplast genome sequences of Fritillaria ussuriensis Maxim. and Fritillaria cirrhosa D. Don, and comparative analysis with other Fritillaria species. Molecules 2017, 22, 982. [CrossRef] [PubMed]

40. Xu, J.H.; Liu, Q.; Hu, W.; Wang, T.; Xue, Q.; Messing, J. Dynamics of chloroplast genomes in green plants. Genomics 2015, 106, 221-231. [CrossRef] [PubMed]

41. Park, I.; Yang, S.; Kim, W.; Noh, P.; Lee, H.; Moon, B. Authentication of herbal medicines Dipsacus asper and Phlomoides umbrosa using DNA barcodes, chloroplast genome, and sequence characterized amplified region (SCAR) Marker. Molecules 2018, 23, 1748. [CrossRef] [PubMed] 
42. Kim, J.H.; Jung, J.-Y.; Choi, H.-I.; Kim, N.-H.; Park, J.Y.; Lee, Y.; Yang, T.-J. Diversity and evolution of major Panax species revealed by scanning the entire chloroplast intergenic spacer sequences. Genet. Resour. Crop Evol. 2013, 60, 413-425. [CrossRef]

43. Magee, A.M.; Aspinall, S.; Rice, D.W.; Cusack, B.P.; Semon, M.; Perry, A.S.; Stefanovic, S.; Milbourne, D.; Barth, S.; Palmer, J.D.; et al. Localized hypermutation and associated gene losses in legume chloroplast genomes. Genome Res. 2010, 20, 1700-1710. [CrossRef] [PubMed]

44. Jansen, R.K.; Cai, Z.; Raubeson, L.A.; Daniell, H.; Depamphilis, C.W.; Leebens-Mack, J.; Muller, K.F.; Guisinger-Bellian, M.; Haberle, R.C.; Hansen, A.K.; et al. Analysis of 81 genes from 64 plastid genomes resolves relationships in angiosperms and identifies genome-scale evolutionary patterns. Proc. Natl. Acad. Sci. USA 2007, 104, 19369-19374. [CrossRef] [PubMed]

45. Moore, M.J.; Bell, C.D.; Soltis, P.S.; Soltis, D.E. Using plastid genome-scale data to resolve enigmatic relationships among basal angiosperms. Proc. Natl. Acad. Sci. USA 2007, 104, 19363-19368. [CrossRef] [PubMed]

46. The Angiosperm Phylogeny Group. An update of the Angiosperm Phylogeny Group classification for the orders and families of flowering plants: APG IV. Bot. J. Linn. Soc. 2016, 181, 1-20. [CrossRef]

47. Sun, F.-J.; Downie, S.; van Wyk, B.-E.; Tilney, P. A molecular systematic investigation of Cymopterus and its allies (Apiaceae) based on phylogenetic analyses of nuclear (ITS) and plastid (rps16 intron) DNA sequences. S. Afr. J. Bot. 2004, 70, 407-416. [CrossRef]

48. Sun, F.-J.; Downie, S.R. Phylogenetic relationships among the perennial, endemic Apiaceae subfamily Apioideae of western North America: Additional data from the cpDNA trnF-trnL-trnT region continue to support a highly polyphyletic Cymopterus. Plant Divers. Evol. 2010, 128, 151-172. [CrossRef]

49. Pimenov, M.G.; Ostroumova, T.A.; Degtjareva, G.V.; Samigullin, T.H. Sillaphyton, a new genus of the Umbelliferae, endemic to the Korean peninsula. Botanica Pacifica 2016, 5, 31-41. [CrossRef]

50. Wu, Z.; Raven, P.H.; Hong, D. Flora of China. Volume 14: Apiaceae through Ericaceae; Science Press: Beijing, China; Missouri Botanical Garden Press: St. Louis, MO, USA, 2005.

51. Lee, Y.N. Flora of Korea; Kyo-Hak Publishing Co.: Seoul, Korea, 2002; 1265p.

52. Makino, T. Observations on the Flora of Japan. (Continued from Vol. XXVII. p. 258.). Shokubutsugaku Zasshi 1914, 28, 20-30. [CrossRef]

53. Kim, K.; Lee, S.C.; Lee, J.; Lee, H.O.; Joh, H.J.; Kim, N.H.; Park, H.S.; Yang, T.J. Comprehensive survey of genetic diversity in chloroplast genomes and $45 \mathrm{~S}$ nrDNAs within Panax ginseng species. PLoS ONE 2015, 10, e0117159. [CrossRef] [PubMed]

54. Hong, S.Y.; Cheon, K.S.; Yoo, K.O.; Lee, H.O.; Cho, K.S.; Suh, J.T.; Kim, S.J.; Nam, J.H.; Sohn, H.B.; Kim, Y.H. Complete chloroplast genome sequences and comparative analysis of Chenopodium quinoa and C. album. Front. Plant Sci. 2017, 8, 1696. [CrossRef] [PubMed]

55. Delcher, A.L.; Salzberg, S.L.; Phillippy, A.M. Using mummer to identify similar regions in large sequence sets. Curr Protoc Bioinformatics 2003, 00, 10.3.1-10.3.18. [CrossRef]

56. Luo, R.; Liu, B.; Xie, Y.; Li, Z.; Huang, W.; Yuan, J.; He, G.; Chen, Y.; Pan, Q.; Liu, Y.; et al. Soapdenovo2: An empirically improved memory-efficient short-read de novo assembler. Gigascience 2012, 1, 18. [CrossRef] [PubMed]

57. Tillich, M.; Lehwark, P.; Pellizzer, T.; Ulbricht-Jones, E.S.; Fischer, A.; Bock, R.; Greiner, S. GeSeq-Versatile and accurate annotation of organelle genomes. Nucleic Acids Res. 2017, 45, W6-W11. [CrossRef] [PubMed]

58. Carver, T.; Berriman, M.; Tivey, A.; Patel, C.; Bohme, U.; Barrell, B.G.; Parkhill, J.; Rajandream, M.A. Artemis and ACT: Viewing, annotating and comparing sequences stored in a relational database. Bioinformatics 2008, 24, 2672-2676. [CrossRef] [PubMed]

59. Lowe, T.M.; Eddy, S.R. tRNAscan-SE: A program for improved detection of transfer RNA genes in genomic sequence. Nucleic Acids Res. 1997, 25, 955-964. [CrossRef] [PubMed]

60. Warburton, P.E.; Giordano, J.; Cheung, F.; Gelfand, Y.; Benson, G. Inverted repeat structure of the human genome: The $\mathrm{X}$-chromosome contains a preponderance of large, highly homologous inverted repeats that contain testes genes. Genome Res. 2004, 14, 1861-1869. [CrossRef] [PubMed]

61. Gurusaran, M.; Ravella, D.; Sekar, K. Repex: Repeat extractor for biological sequences. Genomics 2013, 102, 403-408. [CrossRef] [PubMed] 
62. Lohse, M.; Drechsel, O.; Bock, R. OrganellarGenomeDRAW (OGDRAW): A tool for the easy generation of high-quality custom graphical maps of plastid and mitochondrial genomes. Curr. Genet. 2007, 52, 267-274. [CrossRef] [PubMed]

63. Tamura, K.; Stecher, G.; Peterson, D.; Filipski, A.; Kumar, S. MEGA6: Molecular Evolutionary Genetics Analysis version 6.0. Mol. Biol. Evol. 2013, 30, 2725-2729. [CrossRef] [PubMed]

64. Li, H.; Durbin, R. Fast and accurate long-read alignment with Burrows-Wheeler transform. Bioinformatics 2010, 26, 589-595. [CrossRef] [PubMed]

65. Frazer, K.A.; Pachter, L.; Poliakov, A.; Rubin, E.M.; Dubchak, I. VISTA: Computational tools for comparative genomics. Nucleic Acids Res. 2004, 32, W273-W279. [CrossRef] [PubMed]

66. Librado, P.; Rozas, J. DnaSP v5: A software for comprehensive analysis of DNA polymorphism data. Bioinformatics 2009, 25, 1451-1452. [CrossRef] [PubMed]

67. Thiel, T. MISA-Microsatellite Identification Tool. 2003. Available online: http://misaweb.ipk-gatersleben.de/ (accessed on 2 January 2019).

68. Benson, G. Tandem repeats finder: A program to analyze DNA sequences. Nucleic Acids Res. 1999, $27,573-580$. [CrossRef] [PubMed]

69. Katoh, K.; Misawa, K.; Kuma, K.I.; Miyata, T. MAFFT: A novel method for rapid multiple sequence alignment based on fast fourier transform. Nucleic Acids Res. 2002, 30, 3059-3066. [CrossRef] [PubMed]

70. Hall, T.A. Bioedit: A user-friendly biological sequence alignment editor and analysis program for windows 95/98/nt. Nucleic Acids Symp. Ser. 1999, 41, 95-98.

71. Darriba, D.; Taboada, G.L.; Doallo, R.; Posada, D. jModelTest 2: More models, new heuristics and parallel computing. Nat. Methods 2012, 9, 772. [CrossRef] [PubMed]

72. Ronquist, F.; Teslenko, M.; van der Mark, P.; Ayres, D.L.; Darling, A.; Hohna, S.; Larget, B.; Liu, L.; Suchard, M.A.; Huelsenbeck, J.P. MrBayes 3.2: Efficient Bayesian phylogenetic inference and model choice across a large model space. Syst. Biol. 2012, 61, 539-542. [CrossRef] [PubMed]

Sample Availability: Samples of A. polymorpha and L. officinale are available from the authors and the herbarium of KIOM.

(C) 2019 by the authors. Licensee MDPI, Basel, Switzerland. This article is an open access article distributed under the terms and conditions of the Creative Commons Attribution (CC BY) license (http://creativecommons.org/licenses/by/4.0/). 